\title{
LINGKUNGAN KERJA NON FISIK BERPENGARUH TERHADAP MOTIVASI INTRINSIK DAN KEPUASAN KERJA KARYAWAN
}

\author{
Komang Alit Bagus Putra Pratame ${ }^{1}$ \\ I Wayan Suana ${ }^{2}$ \\ ${ }^{(1)(2)}$ Fakultas Ekonomi dan Bisnis Universitas Udayana, Bali, Indonesia \\ email: alitputra1097@gmail.com
}

\begin{abstract}
ABSTRAK
Kepuasan kerja merupakan cara pandang seseorang baik yang bersifat positif maupun negatif tentang pekerjaannya. Tujuan penelitian adalah untuk menguji pengaruh lingkungan kerja non fisik terhadap motivasi intrinsik dan kepuasan kerja PT. Wibisana Marine Adventure. Penelitian dilakukan di PT. Wibisana Marine Adventure dengan menggunakan sampel sebanyak 48 orang, dengan teknik metode nonprobability sampling yang didalamnya terdapat metode sampling jenuh. Pengumpulan data dilakukan melalui wawancara dan kuesioner. Teknik analisis yang digunakan adalah analisis Jalur. Hasil dari penelitian ini menemukan bahwa lingkungan kerja non fisik berpengaruh positif dan signifikan terhadap motivasi intrinsik. Lingkungan kerja non fisik berpengaruh positif dan signifikan terhadap kepuasan kerja karyawan. Motivasi intrinsik berpengaruh positif dan signifikan terhadap kepuasan kerja karyawan. Implikasi dari hasil penelitian ini adalah ketika lingkungan kerja non fisik yang diperoleh oleh karyawan meningkatkan motivasi intrinsik, maka motivasi intrinsik yang dirasakan oleh karyawan menjadi semakin kuat sehingga berpotensi meningkatkan kepuasan kerja.

Kata kunci : lingkungan kerja non fisik, motivasi intrinsik, kepuasan kerja
\end{abstract}

\begin{abstract}
Job satisfaction is a person's perspective both positive and negative about their work. The purpose of the study was to examine the effect of the non-physical work environment on intrinsic motivation and job satisfaction of PT. Wibisana Marine Adventure. 48 people used as samples, with saturated sampling method. Data collected through interviews and questionnaires and analyzed using Path analysis. The results of this study found that the non-physical work environment had a positive and significant effect on intrinsic motivation. Non-physical work environment has a positive and significant effect on employee job satisfaction. Intrinsic motivation has a positive and significant effect on employee job satisfaction. The implication of the results of this study is that when the non-physical work environment obtained by employees increases intrinsic motivation, the intrinsic motivation felt by employees becomes stronger so that it has the potential to increase job satisfaction. Keywords: non physical work environment, intrinsic motivation, job satisfaction
\end{abstract}




\section{PENDAHULUAN}

Kepuasan karyawan dalam bekerja merupakan faktor penting yang harus diperhatikan oleh organisasi, perhatihan tersebut seperti memberikan kesempatan untuk berkembang dan mengurangi tekanan dalam bekerja, sehingga karyawan dapat merasa nyaman dalam melakukan pekerjaan dan dapat meningkatkan kinerja dari karyawan itu sendiri (Mahmud et al., 2015). Kabungaidze \& Mahlatshana (2015) menyatakan bahwa dengan adanya karyawan yang memiliki kepuasan kerja yang tinggi, maka karyawan tersebut akan setia terhadap pekerjaan yang dilakukannya. Naeem et al. (2015) menyatakan kepuasan kerja sangat penting adanya dalam organisasi karena memiliki dampak yang signifikan. Shurbagi (2015) berpendapat bahwa kepuasan kerja merupakan cara pandang seseorang baik yang bersifat positif maupun negatif tentang pekerjaannya. Setiap individu memiliki tingkat kepuasan yang berbeda-beda sesuai dengan sistem nilai yang berlaku pada dirinya (Hashim et al., 2015). Kepuasan kerja merupakan faktor yang mendorong karyawan lebih tekun dalam bekerja dan sekaligus sebagai motivasi dalam bekerja.

Motivasi kerja merupakan usaha yang dilakukan seseorang untuk menjaga semangat kerja sehingga nantinya dapat meningkatkan kinerja dalam pekerjaan agar lebih produktif (Veronica et al., 2018). Rendahnya kinerja karyawan dapat disebabkan oleh masalah motivasi di dalam suatu perusahaan (Cemal et al., 2015). Faktor motivasi yang akan memengaruhi kinerja yang dimiliki seseorang merupakan potensi, dimana seseorang belum tentu bersedia untuk mengerahkan seluruh potensi yang dimilikinya untuk mencapai hasil yang optimal, sehingga masih diperlukan adanya pendorong agar seseorang karyawan mau menggunakan seluruh potensinya. Rendahnya kinerja karyawan dapat disebabkan oleh masalah motivasi di dalam suatu perusahaan (Celep \& Yilmazturk, 2015). Organisasi harus memotivasi karyawannya untuk kinerja terbaik atau untuk mencapai tujuan organisasi, bahkan motivasi adalah alat terbaik untuk meningkatkan kinerja (Hashim et al., 2015).

Kepuasan kerja mempunyai peran penting dalam rangka mendukung tercapainya kinerja yang baik sesuai dengan standar kinerja dan tujuan perusahaan. Kepuasan kerja ditentukan oleh beberapa faktor pokok yang salah satunya adalah lingkungan kerja. Lingkungan kerja di dalam suatu perusahaan sangat penting untuk diperhatikan pihak manajemen (Raziq \& Maulabakhsh, 2015). Lingkungan kerja sangat berperan penting dalam menciptakan suatu dorongan atau motivasi kepada karyawan agar dapat bekerja lebih baik dalam mencapai tujuan perusahaan. Lingkungan kerja yang baik dapat meningkatkan kinerja dan kepuasan kerja. jenis lingkungan kerja dibagi menjadi lingkungan kerja fisik seperti lingkungan tempat kerja dan lingkungan non fisik seperti suasana kerja (Puangyoykeaw \& Nishide, 2015).

Izzah et al. (2019) menyatakan bahwa lingkungan kerja non fisik adalah semua keadaan berkaitan dengan hubungan kerja seperti hubungan dengan atasan, sesama rekan kerja, atau hubungan dengan bawahan. Lingkungan kerja juga merupakan faktor yang dapat memotivasi karyawan dalam bekerja. Aspek - aspek yang berpengaruh terhadap motivasi kerja, yakni rasa aman dalam bekerja, mendapat gaji yang adil dan kompetitif, lingkungan kerja yang menyenangkan, 
penghargaan atas prestasi kerja, dan perlakuan yang adil dari manajemen. Kenyamanan lingkungan kerja seperti adanya keharmonisan dalam bekerja dapat memicu motivasi kerja pegawai untuk bekerja lebih baik sehingga pekerjaan akan dicapai secara maksimal.

Hasil Penelitian Setyadi et al. (2015) menemukan lingkungan kerja non fisik berpengaruh positif dan signifikan terhadap kepuasan kerja. Suwarsito (2016) menemukan lingkungan kerja non fisik secara signifikan berpengaruh terhadap motivasi kerja karyawan Wahana Visi Indonesia. Pangarso \& Ramadhyanti (2015) menyatakan bahwa lingkungan kerja non fisik berpengaruh positif dan signifikan terhadap kepuasan kerja. Eka et al. (2016) menyatakan hasil dari penelitiannya bahwa lingkungan kerja non fisik berpengaruh positif dan signifikan terhadap kepuasan kerja pada PT. Telkom Indonesia Witel Jatim. Handy \& Riana (2018) dalam penelitiannya menyatakan Motivasi intrinsik memiliki pengaruh positif dan signifikan terhadap kepuasan kerja pada pegawai di dinas pendapatan Daerah Badung Mangusada. Widyaputra \& Dewi (2018) dalam penelitiannya menunjukan bahwa motivasi intrinsik memiliki pengaruh positif signifikan terhadap kepuasan kerja. Hal ini menunjukan bahwa pemberian motivasi intrinsik yang baik kepada karyawan dapat meningkatkan kepuasan kerja karyawan terhadap perusahaaannya.

Tabel 1.

Tingkat Absensi Kerja PT. Wibisana Marine Adventure Periode Januari Desember 2018

\begin{tabular}{|c|c|c|c|c|c|c|}
\hline Bulan & $\begin{array}{c}\text { Jumlah } \\
\text { Tenaga } \\
\text { Kerja } \\
\text { (orang) }\end{array}$ & $\begin{array}{c}\text { Jumlah } \\
\text { Hari } \\
\text { Kerja } \\
\text { (hari) }\end{array}$ & $\begin{array}{c}\text { Jumlah } \\
\text { hari kerja } \\
\text { seharusnya } \\
\text { (hari) }\end{array}$ & $\begin{array}{c}\text { Jumlah } \\
\text { absensi } \\
\text { (hari) }\end{array}$ & $\begin{array}{c}\text { Jumlah } \\
\text { hari kerja } \\
\text { senyatanya } \\
\text { (hari) }\end{array}$ & $\begin{array}{c}\text { Presentasi } \\
\text { Absensi } \\
(\%)\end{array}$ \\
\hline $\mathbf{A}$ & B & $\mathbf{C}$ & $\mathrm{D}=\mathrm{BxC}$ & $\mathbf{E}$ & $F=D-C$ & G=E:Dx100\% \\
\hline Januari & 44 & 26 & 1144 & 35 & 1118 & 3,04 \\
\hline Februari & 44 & 24 & 1056 & 34 & 1032 & 3,27 \\
\hline Maret & 44 & 25 & 1100 & 36 & 1075 & 3,27 \\
\hline April & 44 & 26 & 1144 & 35 & 1118 & 3,04 \\
\hline Mei & 45 & 25 & 1125 & 34 & 1100 & 3,02 \\
\hline Juni & 45 & 26 & 1170 & 35 & 1144 & 2,95 \\
\hline Juli & 46 & 26 & 1196 & 36 & 1170 & 3,01 \\
\hline Agustus & 47 & 25 & 1175 & 35 & 1150 & 2,97 \\
\hline September & 50 & 25 & 1250 & 34 & 1225 & 2,72 \\
\hline Oktober & 50 & 26 & 1300 & 36 & 1274 & 2,72 \\
\hline November & 48 & 24 & 1152 & 34 & 1128 & 2,94 \\
\hline Desember & 48 & 25 & 1200 & 36 & 1175 & 3,00 \\
\hline \multicolumn{2}{|c|}{ Jumlah } & 303 & 14012 & 420 & 13709 & 35,95 \\
\hline \multicolumn{2}{|c|}{ Rata-rata } & & & & & 3,05 \\
\hline
\end{tabular}

Sumber : Data Diolah, 2019 
Penelitian ini dilakukan di sebuah perusahaan yang bergerak di bidang pariwisata, khususnya penyedia jasa atraksi. Perusahaan ini bernama PT. Wibisana Marine Adventure. Lokasi perusahaan ini berada di daerah Tanjung Benoa, Badung, Bali. Perusahaan ini memiliki 48 karyawan yang tersebar di sepuluh departemen. Berdasarkan hasil wawancara dengan manajer perusahaan bahwa pada tahun 2018 hingga 2019 terdapat masalah yang dialami perusahaan terkait motivasi dan kepuasan kerja. Data yang diperoleh dari perusahaan berupa data tingkat absensi yang ditunjukkan pada Tabel 1. dan data keluhan pelanggan yang ditunjukkan pada tabel 2.

Tabel 1. mengindikasikan rendahnya motivasi dan kepuasan kerja karyawan melalui data absensi, dapat dijelaskan bahwa absensi karyawan PT. Wibisana Marine Adventure januari - desember 2018 cenderung berfluktuasi dimana rata rata tingkat absensi karyawan sebesar 3,05 persen. Apabila dilihat dari jumlah karyawan, maka tingkat absensi tergolong tinggi karena jumlah karyawan pada PT. Wibisana Marine Adventure adalah sebanyak 48 orang.

\section{Tabel 2}

Data Keluhan Pelanggan PT. Wibisana Marine Adventure

\section{Tipe Keluhan Pelanggan}

\begin{tabular}{lcccc}
\cline { 2 - 5 } Bulan & $\begin{array}{c}\text { Kurangnya } \\
\text { kualitas pelayanan pengetahuan bahasa } \\
\text { (orang) }\end{array}$ & $\begin{array}{c}\text { Kurangnya } \\
\text { Inggris (orang) }\end{array}$ & $\begin{array}{c}\text { Rendahnya } \\
\text { ketepatan waktu } \\
\text { pelayanan (orang) }\end{array}$ & $\begin{array}{c}\text { Kepedulian } \\
\text { karyawan } \\
\text { (orang) }\end{array}$ \\
\hline Januari & 1 & 0 & 1 & 0 \\
Februari & 0 & 2 & 1 & 1 \\
Maret & 2 & 1 & 6 & 2 \\
April & 2 & 0 & 3 & 3 \\
Mei & 3 & 1 & 7 & 1 \\
Juni & 2 & 3 & 2 & 2 \\
Juli & 1 & 0 & 2 & 2 \\
Agustus & 3 & 2 & 4 & 12 \\
Total & 13 & 8 & 26 & \\
\hline
\end{tabular}

Sumber : Data Diolah, 2019

Tabel 2. mengindikasikan rendahnya motivasi intrinsik melalui data keluhan pelanggan yang datang ke PT. Wibisana Marine Adventure berdasarkan kurangnya kualitas pelayanan, kurangnya pengetahuan bahasa Inggris, rendahnya ketepatan waktu pelayanan, dan kepedulian karyawan. Total keluhan selama delapan bulan terakhir sebanyak 59 keluhan, keluhan terbesar terdapat pada rendahnya ketepatan waktu pelayanan yang dirasakan oleh pelanggan.

Hal yang sebaliknya terjadi pada lokasi penelitian di PT. Wibisana Marine Adventure, terlihat kepuasan kerja karyawannya masih kurang sehingga mengganggu kinerja pelayanan karyawan. Rendahnya kepuasan kerja karyawan dapat diketahui berdasarkan hasil wawancara dengan manajer dari PT. Wibisana Marine Adventure mengenai indikasi kepuasan kerja karyawan, dimana dalam satu bidang salah satu karyawan merasa kurang nyaman atas tindakan karyawan lain yang biasanya memberikan beban kerja yang lebih. Pihak perusahaan harus 
memperhatikan kondisi ini agar kinerja yang diberikan karyawan kepada perusahaan tidak terganggu dan dapat berjalan dengan optimal.

Tujuan penelitian berdasarkan rumusan masalah diatas adalah mengetahui pengaruh lingkungan kerja non fisik terhadap motivasi intrinsik di PT. Wibisana Marine Adventure, pengaruh lingkungan kerja non fisik terhadap kepuasan kerja di PT. Wibisana Marine Adventure dan pengaruh motivasi intrinsik terhadap kepuasan kerja di PT. Wibisana Marine Adventure

Penelitian ini didasari oleh teori pertukaran sosial (exchange theory), teori pertukaran sosial adalah teori yang paling penting untuk memahami perilaku seseorang di tempat kerja. Hande et al. (2015) mengemukakan bahwa hubungan di tempat kerja memiliki unsur-unsur dari teori pertukaran sosial. Seorang pemimpin perusahaan yang mengetahui keinginan karyawan dan dapat menjelaskan apa yang akan diperoleh jika hasil kerjanya sesuai dengan harapan seperti memberikan imbalan yang sebanding dengan kinerjanya, maka karyawan akan berusaha untuk menunjukan kinerjanya yang baik secara maksimal. Teori ini menjelaskan ketika pemimpin mengetahui apa yang masing-masing karyawan butuhkan dalam mencapai kinerja maksimal. Setyadi et al. (2015) menemukan lingkungan kerja non fisik berpengaruh positif dan signifikan terhadap kepuasan kerja. Suwarsito (2016) menemukan lingkungan kerja non fisik secara signifikan berpengaruh terhadap motivasi kerja karyawan Wahana Visi Indonesia. Handy \& Riana (2018) dalam penelitiannya menyatakan lingkungan kerja non fisik memiliki pengaruh positif dan signifikan terhadap motivasi intrinsik pada pegawai di dinas pendapatan Daerah Badung Mangusada.

$\mathrm{H}_{1}$ : Lingkungan kerja non fisik berpengaruh positif dan signifikan terhadap motivasi intrinsik karyawan.

Jain \& Kaur (2015) dalam penelitiannya menemukan bahwa beban kerja, setres, lembur, kelelahan, kebosanan adalah beberapa faktor untuk meningkatkan ketidak puasan kerja. Pada fasilitas kondisi kerja yang baik sisi lain, penyegaran dan fasilitas rekreasi, kesehatan dan keselamatan, menyenangkan di tempat kerja meningkatkan tingkat kepuasan kerja. Osibanjo et al. (2015) menemukan bahwa menyediakan lingkungan kerja yang kondusif, cukup terjamin dan memastikan menyeimbangkan pekerjaan dengan keluarga dan memastikan bahwa beban pekerjaan tidak melebihi batas.

Pangarso \& Ramadhyanti (2015) menyatakan bahwa lingkungan kerja non fisik berpengaruh positif dan signifikan terhadap kepuasan kerja. Eka et al. (2016) menyatakan hasil dari penelitiannya bahwa lingkungan kerja non fisik berpengaruh positif dan signifikan terhadap kepuasan kerja pada PT. Telkom Indonesia Witel Jatim. Handy \& Riana (2018) menyatakan lingkungan kerja non fisik memiliki pengaruh positif dan signifikan terhadap kepuasan kerja pada pegawai di dinas pendapatan Daerah Badung Mangusada.

$\mathrm{H}_{2}$ : Lingkungan kerja non fisik berpengaruh positif dan signifikan terhadap kepuasan kerja karyawan.

Motivasi dalam cangkupannya secara intrinsik dan ekstrinsik merupakan faktor penting dalam menentukan kepuasan dan kinerja karyawan. Ibrahim \& Brobbey (2015) menyatakan tentang motivasi, dimana motivasi ini bersifat individual karena kebutuhan individu berbeda-beda dan oleh karena itu harus 
ditargetkan pada kebutuhan individu dan kelompok secara intrinsik yang akan lebih memuaskan karyawan dalam bekerja. Guritno \& Prabowo (2016) menyatakan bahwa dalam penelitiannya pada karyawan PT JHOS GF Semarang bahwa semakin tinggi motivasi instrinsik yang dimiliki karyawan makan akan meningkatkan kepuasan kerja karyawan terhadap pekerjaannya. Bahrulmazi \& Thiam (2015) menunjukkan bahwa adanya pengaruh positif antara motivasi intrinsik terhadap kepuasan kerja.

Hasil penelitian Sariningtyas (2016) menunjukkan bahwa adanya pengaruh positif antara motivasi intrinsik terhadap kepuasan kerja. Taufiq (2016) menyatakan bahwa motivasi intrinsik berpengaruh positif dan signifikan terhadap kepuasan kerja. Handy \& Riana (2018) dalam penelitiannya menyatakan Motivasi intrinsik memiliki pengaruh positif dan signifikan terhadap kepuasan kerja pada pegawai di dinas pendapatan Daerah Badung Mangusada. Widyaputra \& Dewi (2018) dalam penelitiannya menunjukan bahwa motivasi intrinsik memiliki pengaruh positif signifikan terhadap kepuasan kerja. Hal ini menunjukan bahwa pemberian motivasi intrinsik yang baik kepada karyawan dapat meningkatkan kepuasan kerja karyawan terhadap perusahaaannya.

$\mathrm{H}_{3}$ : Motivasi intrinsik berpengaruh positif dan signifikan terhadap kepuasan kerja karyawan.

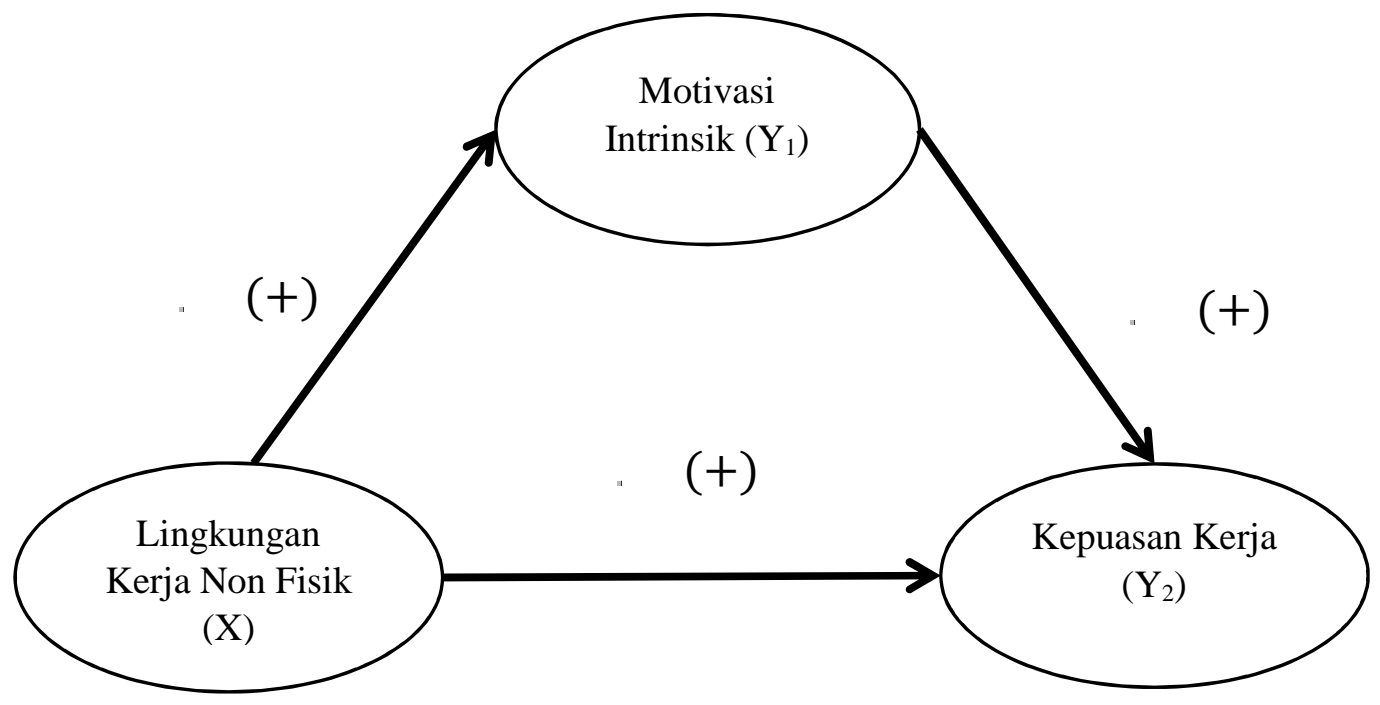

Gambar 1. Kerangka Konseptual

Penelitian ini dilakukan untuk mengetahui hubungan antara variabel lingkungan kerja non fisik, motivasi intrinsik, dan kepuasan kerja. Hubungan antara variabel tersebut dapat dilihat ketika lingkungan kerja non fisik mampu meningkatkan kepuasan kerja melalui motivasi intrinsik pada masing-masing karyawan. Hubungan tersebut juga berkaitan dengan teori pertukaran sosial dimana terciptanya lingkungan kerja non fisik yang baik berupa terciptanya hubungan yang baik antara atasan dan bawahan, hubungan yang baik antara sesama rekan kerja mampu meningkatkan motivasi yang dimiliki karyawan, 
sehingga memberikan timbal balik yang positif terhadap kepuasaan kerja karyawan yang semakin meningkat.

\section{METODE PENELITIAN}

Penelitian ini menggunakan pendekatan kuantitatif yang bersifat asosiatif. Lokasi penelitian bertempat di PT. Wibisana Marine Adventure di Tanjung Benoa, Badung, Bali. Alasan yang melatar belakangi peneliti melakukan penelitian di PT. Wibisana Marine Adventure adalah adanya akses yang memudahkan peneliti untuk mendapatkan informasi yang dibutuhkan dalam penelitian ini. Subyek dalam penelitian ini adalah seluruh karyawan pada PT. Wibisana Marine Adventure yang terdiri dari karyawan Office, Guest Relation Officer (GRO), Marketing, Diving, Watersport, Adventure, Jetski, Kitchen, Glass Buttom Boat (GBB), Driver, Cleaning Service. Obyek dalam penelitian ini adalah Lingkungan kerja non fisik, Motivasi intrinsik, dan Kepuasan Kerja karyawan PT. Wibisana Marine Adventure. Variabel Bebas dalam penelitian ini adalah Lingkungan kerja non fisik (X). Variabel Terikat dalam penelitian ini adalah Motivasi intrinsik $\left(\mathrm{Y}_{1}\right)$ dan kepuasan kerja $\left(\mathrm{Y}_{2}\right)$.

Kepuasan kerja dalam penelitian ini adalah sikap positif maupun negatif individu terhadap suatu pekerjaan yang dilakukannya serta dikatakan juga sebagai perasaan karyawan mengenai senang atau tidaknya mereka terhadap pekerjaan tersebut. Puangyoykeaw \& Nishide (2015) menyatakan indikator yang digunakan untuk mengukur lingkungan kerja non fisik adalah 1) Pekerjaan itu sendiri ( $\left.\mathrm{Y}_{2.1}\right)$ adalah seberapa besar pekerjaan itu dapat memberikan kepuasan bagi pekerja itu sendiri. Diukur dari persepsi responden pekerjaan yang dilakukan sesuai dengan kemampuan karyawan pada PT. Wibisana Marine Adventure. 2) Gaji ( $\left.\mathrm{Y}_{2.2}\right)$ merupakan persepsi tentang balas jasa yang diterima sesuai dengan harapan. Diukur dari persepsi responden gaji yang didapatkan sesuai dengan pekerjaan pada PT. Wibisana Marine Adventure. 3) Atasan ( $\left.\mathrm{Y}_{2.3}\right)$ merupakan kemampuan untuk memberikan arahan serta motivasi kepada karyawan. Diukur dari persepsi responden atasan mampu memberikan arahan serta motivasi pada PT. Wibisana Marine Adventure. 4) Promosi $\left(\mathrm{Y}_{2.4}\right)$ adalah kesempatan setiap karyawan untuk dapat menaikan jenjang karirnya. Diukur dari persepsi responden atasan memberikan peluang untuk memberikan promosi karyawan pada PT. Wibisana Marine Adventure. 5) Rekan kerja $\left(\mathrm{Y}_{2.5}\right)$ yaitu pola interaksi yang terjalin dengan baik antar individu dengan rekan kerja dalam suatu organisasi. Diukur dari persepsi responden memiliki hubungan yang baik dengan rekan kerja pada PT. Wibisana Marine Adventure.

Motivasi intrinsik dalam penelitian ini adalah pendorong kerja yang bersumber dari dalam diri pekerja sebagai individu, berupa kesadaran mengenai pentingnya pekerjaan yang dilaksanakan. Wing, dalam Handy (2018) menyatakan ada tiga indikator motivasi intrinsik, antara lain: Pencapaian hasil tugas $\left(\mathrm{Y}_{1.1}\right)$, Kepuasan individu ( $\left.\mathrm{Y}_{1.2}\right)$, Keikutsertaan anggota pada setiap aktivitas perusahaan $\left(\mathrm{Y}_{1.3}\right)$.

Lingkungan kerja non fisik dalam penelitian ini adalah semua keadaan yang berkaitan dengan hubungan pekerjaan seperti hubungan dengan atasan, sesama 
rekan kerja, atau hubungan dengan bawahan. DeStefano et al. (2006) menyatakan indikator yang digunakan untuk mengukur lingkungan kerja non fisik adalah sebagai berikut 1) Prosedur kerja $\left(\mathrm{X}_{1.1}\right)$ merupakan rangkaian tata pelaksanaan kerja yang diatur secara beruntun, sehingga terbentuk urutan kerja secara bertahap dalam menyelesaikan suatu pekerjaan. 2) Standar kerja $\left(\mathrm{X}_{1.2}\right)$ adalah persyaratan tugas, fungsi atau perilaku yang ditetapkan oleh pemberi kerja sebagai sasaran yang harus dicapai oleh seorang karyawan. 3) Pertanggung jawaban supervisor $\left(\mathrm{X}_{1.3}\right)$ adalah tanggung jawab seorang supervisor untuk menyusun tugas karyawan agar dapat dikerjakan secara efektif dan adil. 4) Kejelasan tugas $\left(\mathrm{X}_{1.4}\right)$ adalah sejauh mana pekerjaan itu menuntut diselesaikannya seluruh potongan kerja secara utuh dan dapat dikenali oleh karyawan. 5) Sistem penghargaan (reward system) $\left(\mathrm{X}_{1.5}\right)$ adalah sebuah program yang digunakan untuk mengenali prestasi individual karyawan, seperti pencapaian sasaran atau proyek atau penggunaan ide-ide kreatif. 6) Hubungan antar karyawan $\left(\mathrm{X}_{1.6}\right)$ yaitu hubungan dengan rekan kerja yang harmonis dan tanpa ada saling intrik diantara sesama rekan kerja.

Data primer dalam penelitian ini adalah data yang dikumpulkan secara langsung dari objek penelitian. Data yang diperoleh dari wawancara dengan beberapa karyawan PT. Wibisana Marine Adventure. Populasi dan sampel dalam penelitian ini adalah karyawan PT. Wibisana Marine Adventure sebanyak 48 orang yang terbagi dalam delapan departemen. Metode yang digunakan dalam penentuan sampel adalah metode sampling jenuh. Pengumpulan data dalam penelitian ini dilakukan dengan menggunakan Wawancara dan Kuesioner.

\section{HASIL DAN PEMBAHASAN}

Wibisana Marine Adventure merupakan sebuah perusahaan swasta yang bergerak dibidang penyedia jasa pariwisata yang berbasis pada atraksi pariwisata, yang berdiri sejak tahun 2005. Perusahaan ini beralamat di Jalan Pratama, Margi Pemuunan, Tanjung Benoa, Badung, Bali. Awal mula tercetusnya Wibisana Marine Adventure diawali dengan bertemunya Bapak I Made Suryana yang merupakan pemilik perusahaan dengan investor yang berkewarganegaraan Inggris. Wibisana Marine Adventure memiliki beberapa jenis permainan yang ditawarkan, yaitu: Glass Bottom Boat, Snorkelling, Diving, Banana Boat, Fly Board, Parasailing Adventure, Fly Fish, Wibi Wake Sliding, Jetski, Seawalker.

Berdasarkan Tabel 3. dapat dilihat jumlah karyawan PT. Wibisana Marine Adventure yang di jadikan sampel sebanyak 48 orang. Jika di lihat dari jenis kelamin, jenis kelamin laki-laki mendominasi dalam penelitian ini yaitu sebanyak 36 orang dengan presentase sebesar 75 persen, sedangkan sisanya perempuan sebanyak 12 orang dengan persentase sebesar 25 persen. Hal ini dikarenakan beban kerja yang ada di PT. Wibisana Marine Adventure. Jika dilihat dari usia, responden yang memiliki usia antara 21 - 30 tahun mendominasi dengan presentase sebesar 56,25 persen, sedangkan untuk kelompok usia terendah yaitu pada usia $>30$ tahun dengan persentase 20,83 persen. Hal ini menunjukkan bahwa karyawan di PT. Wibisana Marine Adventure didominasi oleh karyawan dengan usia yang sangat produktif yaitu 21 - 30 tahun. 
Jika di lihat dari tingkat pendidikan, responden yang memiliki tingkat pendiddikan terakhir SMA sebanyak 35 orang dengan persentase 72,92 persen, Diploma sebanyak 8 orang dengan persentase 16,67 persen. Dan kelompok pendidikan S1 memiliki tingkat responden sebanyak 5 orang dengan persentase 10,42 persen. Hal ini menunjukkan bahwa karyawan di PT. Wibisana Marine Adventure sebagian besar berpendidikan SMA yang merupakan karyawan pada jabatan pengoperasian permainan, karena pada jabatan ini tidak diperlukan tingkat pendidikan yang tinggi.

Tabel 3.

Karakteristik Responden

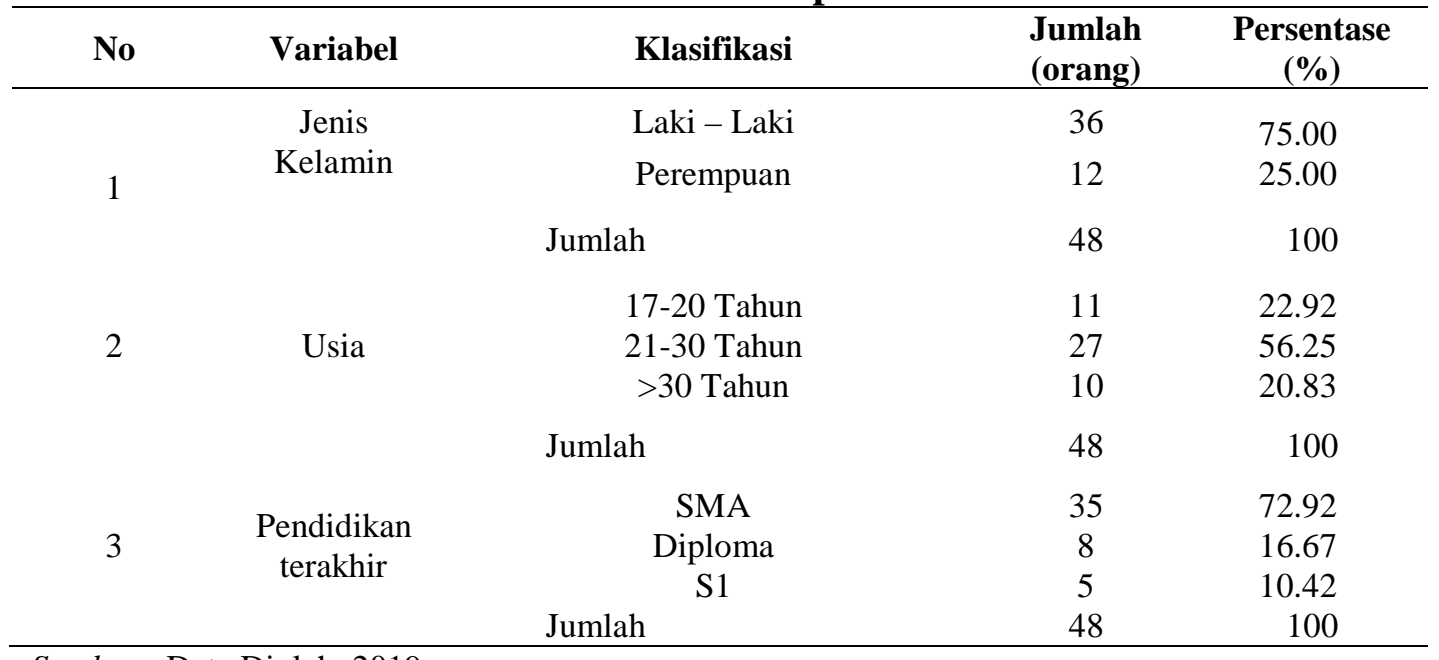

Sumber : Data Diolah, 2019

Tabel 4.

Hasil Uji Validitas

\begin{tabular}{|c|c|c|c|}
\hline No. & Variabel & Instrumen & $\begin{array}{c}\text { Pearson } \\
\text { Correlation }\end{array}$ \\
\hline \multirow{7}{*}{1.} & \multirow{7}{*}{ Lingkungan Kerja Non Fisik (X) } & $\mathrm{X} 1$ & 0,884 \\
\hline & & $\mathrm{X} 2$ & 0,909 \\
\hline & & $\mathrm{X} 3$ & 0,892 \\
\hline & & $\mathrm{X} 4$ & 0,883 \\
\hline & & $\mathrm{X} 5$ & 0,906 \\
\hline & & $\mathrm{X} 6$ & 0,793 \\
\hline & & Y1.1 & 0,959 \\
\hline \multirow[t]{3}{*}{2.} & Motivasi Intrinsik (Y1) & Y1.2 & 0,924 \\
\hline & & Y1.3 & 0,958 \\
\hline & & Y2.1 & 0,847 \\
\hline \multirow{4}{*}{3.} & Kepuasan Keria (Y2) & Y2.2 & 0,922 \\
\hline & nepuasan netja (12) & Y2.3 & 0,873 \\
\hline & & Y2.4 & 0,939 \\
\hline & & Y2.5 & 0,842 \\
\hline
\end{tabular}

Sumber : Data Diolah, 2019

Dapat dinyatakan pada Tabel 4. bahwa seluruh instrumen variabel penelitian berupa lingkungan kerja non fisik, motivasi intrinsik dan kepuasan 
kerja telah memenuhi syarat uji validitas yang dimana nilai skor total pearson correlation masing-masing instrumen berada diatas 0,30 dan mimiliki nilai signifikansi yang lebih kecil dari 5 persen $(0,05)$, maka instrumen layak digunakan menjadi alat ukur variabel-variabel tersebut.

Tabel 5.

Uji Reliabilitas

\begin{tabular}{llc}
\hline \multicolumn{1}{c}{ No. } & \multicolumn{1}{c}{ Variabel } & Cronbach'sAlpha \\
\hline 1. & Lingkungan Kerja Non Fisik(X) & 0,938 \\
3. & Motivasi Intrinsik (Y1) & 0,941 \\
4. & Kepuasan Kerja (Y2) & 0,930 \\
\hline \multicolumn{2}{l}{ Sumber $:$ Data Diolah, 2019 }
\end{tabular}

Tabel 5. ditampilkan uji reliabilitas pada masing-masing variabel berada pada titik diatas 0,60 yang ditunjukkan pada hasil cronbach's alpha, maka dapat dikatakan seluruh instrumen telah memenuhi syarat reliabilitas

Tabel 6.

Deskripsi Jawaban Responden Terhadap Lingkungan Kerja Non Fisik

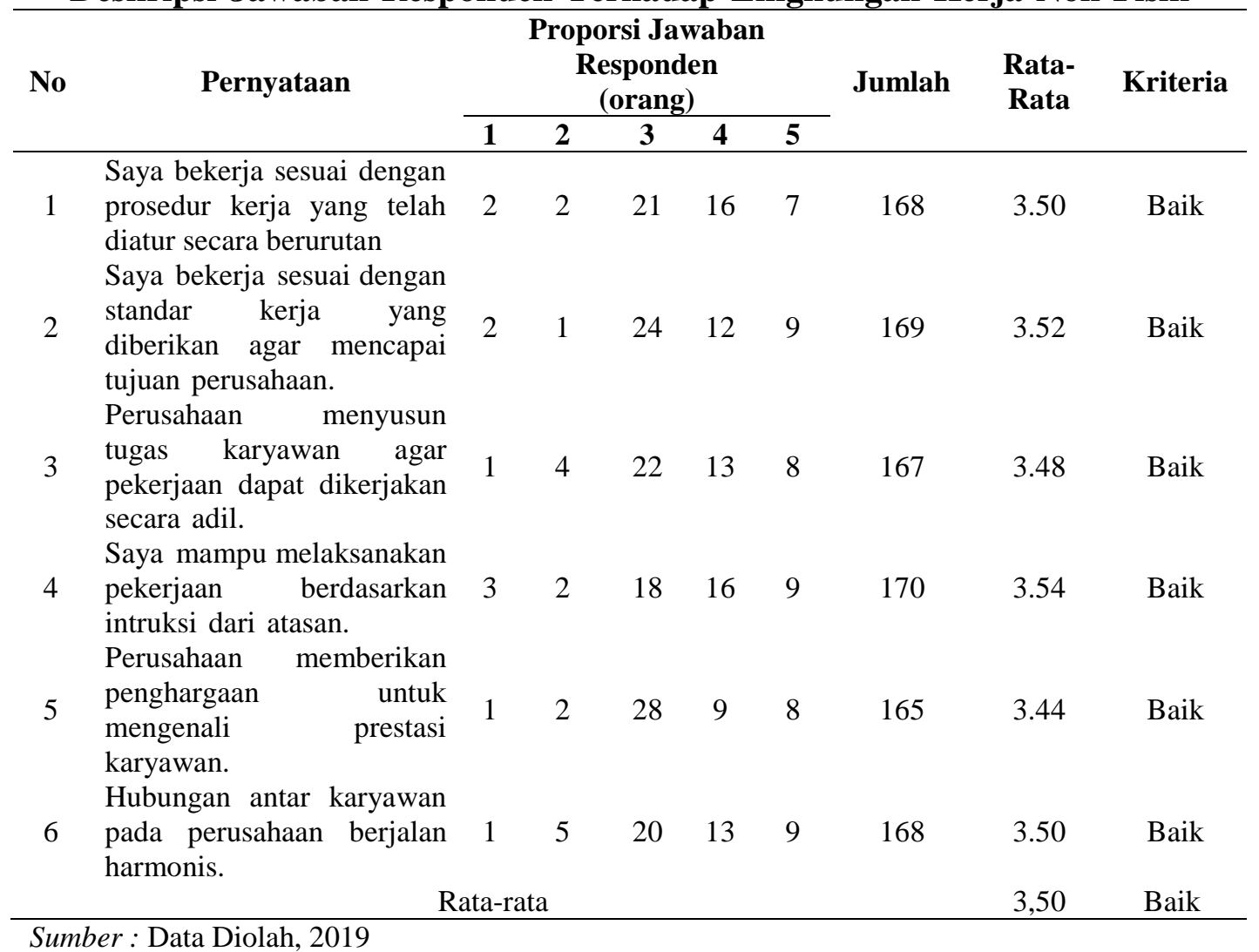

Variabel lingkungan kerja non fisik yang memiliki rata-rata terendah adalah pernyataan "Perusahaan memberikan penghargaan untuk mengenali prestasi karyawan.", diperoleh nilai rata-rata sebesar 3,44 yang masuk kriteria baik, tetapi memiliki nilai rata-rata yang rendah dibandingkan dengan 
pernyataan yang lainnya ini berarti secara umum responden menganggap Perusahaan belum memberikan penghargaan untuk mengenali prestasi karyawan. Variabel lingkungan kerja non fisik yang memiliki rata-rata tertinggi adalah pernyataan "Saya mampu melaksanakan pekerjaan berdasarkan intruksi dari atasan.", diperoleh nilai rata-rata sebesar 3,54 yang masuk kriteria baik, ini berarti secara umum responden mampu melaksanakan pekerjaan berdasarkan intruksi dari atasan.

Tabel 7.

Deskripsi Jawaban Responden Terhadap Motivasi Intrinsik

\begin{tabular}{|c|c|c|c|c|c|c|c|c|c|}
\hline \multirow[t]{2}{*}{ No } & \multirow[t]{2}{*}{ Pernyataan } & \multicolumn{5}{|c|}{$\begin{array}{c}\text { Proporsi Jawaban } \\
\text { Responden } \\
\text { (orang) }\end{array}$} & \multirow[t]{2}{*}{ Jumlah } & \multirow[t]{2}{*}{$\begin{array}{l}\text { Rata- } \\
\text { Rata }\end{array}$} & \multirow[t]{2}{*}{ Kriteria } \\
\hline & & 1 & 2 & 3 & 4 & 5 & & & \\
\hline 1 & $\begin{array}{lr}\text { Saya diberi } & \text { kesempatan } \\
\text { berpartisipasi } & \text { dalam } \\
\text { mencapai tujuan yang } \\
\text { optimal. }\end{array}$ & 2 & 10 & 17 & 12 & 7 & 156 & 3.25 & $\begin{array}{c}\text { Cukup } \\
\text { Kuat }\end{array}$ \\
\hline 2 & $\begin{array}{l}\text { Organisasi memberikan } \\
\text { promosi untuk kinerja } \\
\text { pegawai. }\end{array}$ & 0 & 14 & 17 & 11 & 6 & 153 & 3.19 & $\begin{array}{c}\text { Cukup } \\
\text { Kuat }\end{array}$ \\
\hline 3 & $\begin{array}{lr}\text { Organisasi } & \text { ini } \\
\text { pegawai } & \text { denganan } \\
\text { memberikan } & \text { pelatihan } \\
\text { untuk } & \text { keberhasilan } \\
\text { pegawai. } & \end{array}$ & 2 & 6 & 21 & 12 & 7 & 160 & 3.33 & $\begin{array}{c}\text { Cukup } \\
\text { Kuat }\end{array}$ \\
\hline \multicolumn{7}{|c|}{ Rata-rata } & & 3,26 & $\begin{array}{c}\text { Cukup } \\
\text { Kuat }\end{array}$ \\
\hline
\end{tabular}

Sumber : Data Diolah, 2019

Variabel motivasi intrinsik yang memiliki rata-rata terendah adalah pernyataan "Organisasi memberikan promosi untuk kinerja pegawai.", diperoleh nilai rata-rata sebesar 3,19 yang masuk kriteria cukup kuat, tetapi memiliki nilai rata-rata yang rendah dibandingkan dengan pernyataan yang lainnya ini berarti secara umum responden menganggap Organisasi belum memberikan promosi untuk kinerja pegawai. Variabel motivasi intrinsik yang memiliki rata-rata tertinggi adalah pernyataan "Organisasi ini memotivasi pegawai dengan memberikan pelatihan untuk keberhasilan pegawai", diperoleh nilai rata-rata sebesar 3,33 yang masuk kriteria cukup kuat, ini berarti secara umum responden menganggap Organisasi ini memotivasi pegawai dengan memberikan pelatihan untuk keberhasilan pegawai.

Variabel kepuasan kerja pada Tabel 8. yang memiliki rata-rata terendah adalah pernyataan "Saya merasa puas dengan pekerjaan yang dilakukan", diperoleh nilai rata-rata sebesar 3,10 yang masuk kriteria cukup tinggi, tetapi memiliki nilai rata-rata yang rendah dibandingkan dengan pernyataan yang lainnya ini berarti secara umum responden belum merasa puas dengan pekerjaan 
yang dilakukan. Variabel kepuasan kerja yang memiliki rata-rata tertinggi adalah pernyataan "Saya merasa puas dengan situasi kerja", diperoleh nilai ratarata sebesar 3,33 yang masuk kriteria cukup tinggi, ini berarti secara umum responden merasa puas dengan situasi kerja.

Tabel 8.

Deskripsi Jawaban Responden Terhadap Kepuasan Kerja

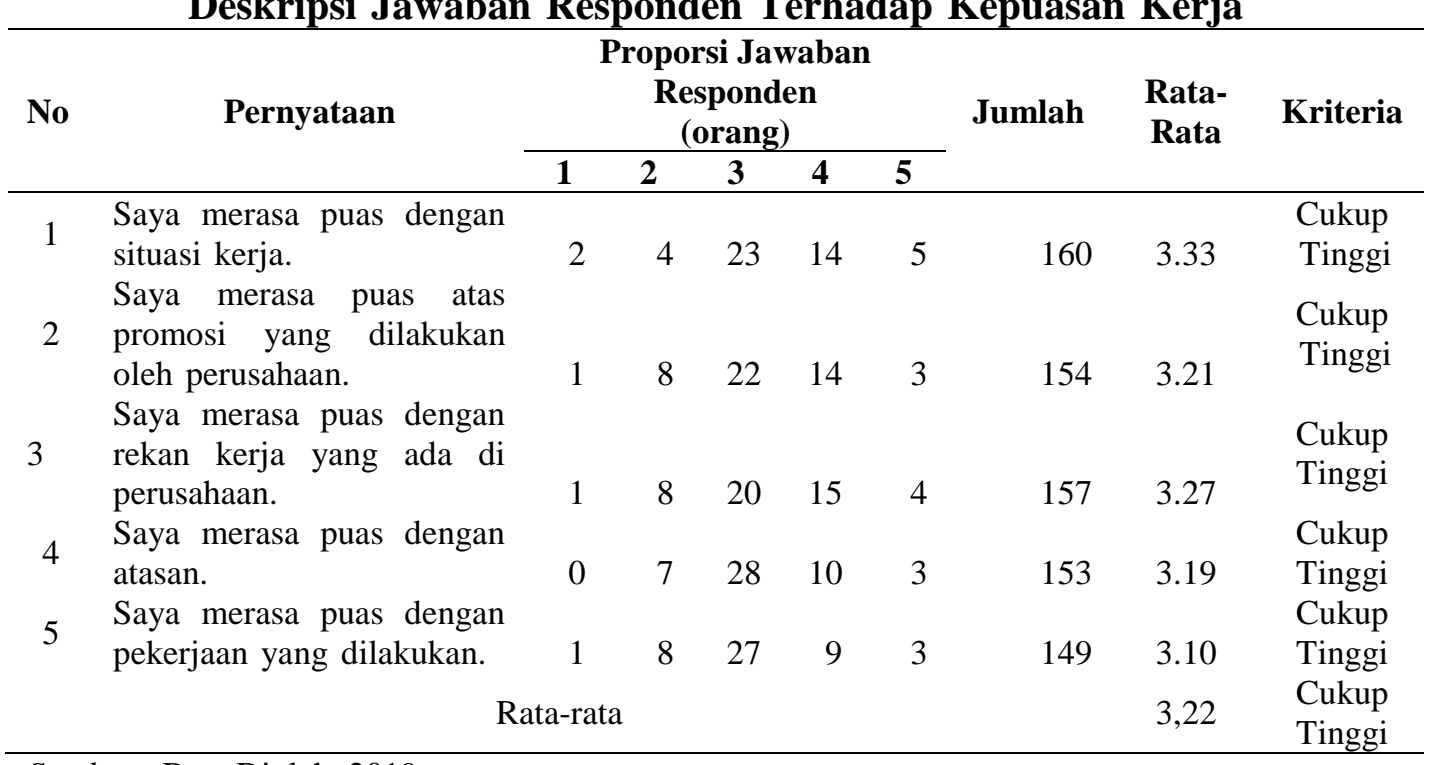

Sumber : Data Diolah, 2019

Tabel 9.

Uji Normalitas

\begin{tabular}{ll}
\hline Persamaan & Kolmogorov-Smirnov Z \\
\hline Substruktur 1 & 0,347 \\
Substruktur 2 & 0,787 \\
\hline
\end{tabular}

Sumber : Data Diolah, 2019

Berdasarkan uji normalitas dengan menggunakan one-sample kolmogorovsmirnov Test yang ditampilkan pada Tabel 9. tersebut menunjukkan bahwa besarnya nilai kolmogorov-smirnov adalah sebesar 0,347 dan 0,787. dapat disimpulkan bahwa model memenuhi asumsi normalitas.

Berdasarkan Tabel 10. tersebut ditunjukkan bahwa tidak terdapat variabel bebas yang memiliki nilai tolerance kurang dari 0,10 dan juga tidak ada variabel bebas yang memiliki nilai VIF lebih dari 10. Maka dari pada itu model regresi bebas dari gejala multikoleniaritas.

Berdasarkan Tabel 11. tersebut, ditunjukkan bahwa masing-masing model memiliki nilai signifikansi lebih besar dari 5 persen. Hal ini menunjukkan bahwa variabel bebas yang digunakan pada penelitian ini tidak berpengaruh secara signifikan terhadap variabel terikatnya yaitu absolute error, maka dari itu, penelitian ini bebas dari gejala heteroskedastisita. 
Tabel 10.

Uji Multikolinieritas

\begin{tabular}{llcc}
\hline & \multicolumn{1}{c}{ Model } & \multicolumn{2}{c}{ Collinearity Statistics } \\
\cline { 3 - 4 } & & Tolerance & VIF \\
\hline \multirow{3}{*}{ Substruktur2 } & Lingkungan Kerja Non & 0.632 & 1.582 \\
& Fisik & 0.632 & 1.582 \\
\hline
\end{tabular}

Sumber : Data Diolah, 2019

Tabel 11.

Uji Heteroskedastisitas (Uji Glesjer)

\begin{tabular}{clcc}
\hline Persamaan & \multicolumn{1}{c}{ Model } & T & Sig. \\
\hline Substruktur1 & Lingkungan Kerja Non Fisik & -0.141 & 0.888 \\
& Lingkungan Kerja Non Fisik & 1.160 & 0.136 \\
Substruktur 2 & Motivasi Intrinsik & 0.021 & 0.983 \\
\hline
\end{tabular}

Sumber : Data Diolah, 2019

Tabel 12.

Hasil Analisis Jalur Pada Struktur 1

\begin{tabular}{|c|c|c|c|c|c|c|}
\hline \multirow{2}{*}{\multicolumn{2}{|c|}{ Model }} & \multicolumn{2}{|c|}{ Unstandardized Coefficients } & \multirow{2}{*}{$\begin{array}{c}\begin{array}{c}\text { Standardized } \\
\text { Coefficients }\end{array} \\
\text { Beta }\end{array}$} & \multirow[t]{2}{*}{$\mathbf{T}$} & \multirow[t]{2}{*}{ Sig. } \\
\hline & & B & Std. Error & & & \\
\hline (Constant) & & 2.453 & 1.455 & & 1.686 & 0.099 \\
\hline $\begin{array}{l}\text { Lingkungan } \\
\text { Non Fisik }\end{array}$ & Kerja & 0.349 & 0.067 & 0.607 & 5.174 & 0.000 \\
\hline $\mathrm{R}^{2}$ & & & & & & \\
\hline
\end{tabular}

Variabel lingkungan kerja non fisik memiliki koefisien sebesar 0,607 berarti lingkungan kerja non fisik memiliki pengaruh positif terhadap motivasi intrinsik.

Variabel lingkungan kerja non fisik pada Tabel 13. memiliki koefisien sebesar 0,307 berarti lingkungan kerja non fisik memiliki pengaruh positif terhadap kepuasan kerja. Variabel motivasi intrinsik memiliki koefisien sebesar 0,454 berarti motivasi intrinsik memiliki pengaruh positif terhadap kepuasan kerja. Lingkungan kerja non fisik memiliki nilai Beta sebesar 0,607 dan nilai Sig. sebesar 0,000, maka dapat dikatakan $\mathrm{H}_{1}$ diterima karena nilai Sig. 0,000 < 0,05. Dengan demikian dapat diartikan lingkungan kerja non fisik berpengaruh positif dan signifikan terhadap motivasi intrinsik, dengan kata lain semakin baik 
lingkungan kerja non fisik maka motivasi intrinsik PT. Wibisana Marine Adventure akan semakin meningkat. Sehingga hipotesis pertama diterima.

Tabel 13.

Hasil Analisis Jalur Pada Struktur 2

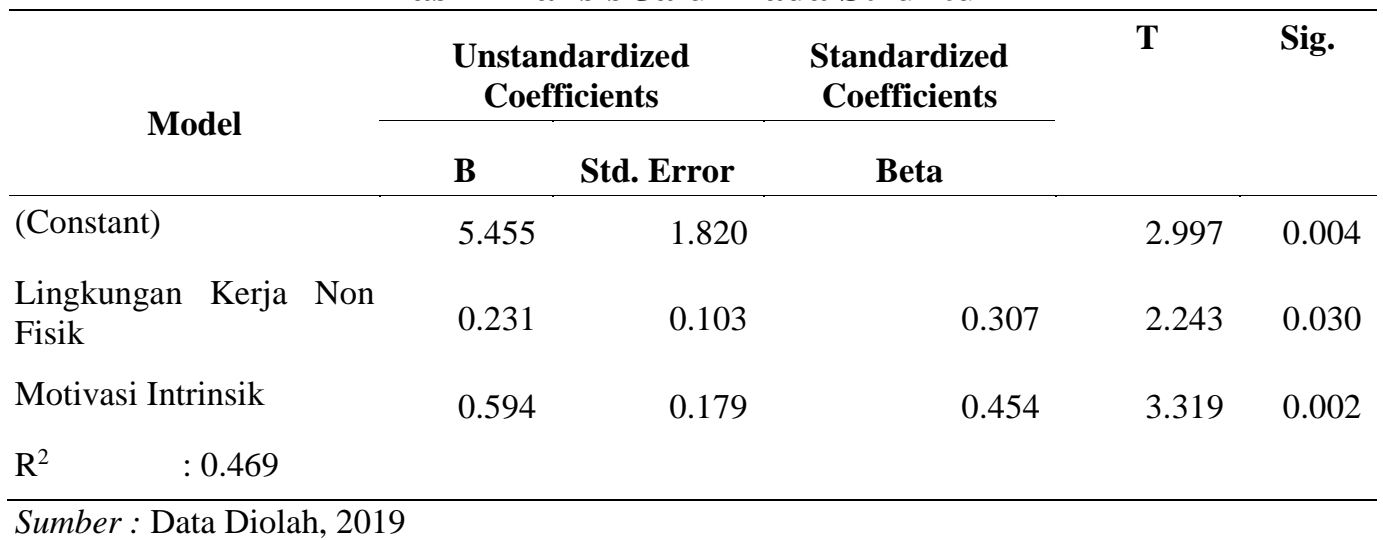

Lingkungan kerja non fisik memiliki nilai Beta sebesar 0,307 dan nilai Sig. sebesar 0,030, maka dapat dikatakan $\mathrm{H}_{2}$ diterima karena nilai Sig. 0,030< 0,05. Dengan demikian dapat diartikan lingkungan kerja non fisik berpengaruh positif dan signifikan terhadap kepuasan kerja, dengan kata lain semakin baik lingkungan kerja non fisik maka kepuasan karyawan PT. Wibisana Marine Adventure akan semakin meningkat. Sehingga hipotesis kedua diterima. Motivasi intrinsik memiliki nilai Beta sebesar 0,454 dan nilai Sig. sebesar 0.002, maka dapat dikatakan $\mathrm{H}_{3}$ diterima karena nilai Sig. $0.002<0,05$. Dengan demikian dapat diartikan motivasi intrinsik berpengaruh positif dan signifikan terhadap kepuasan kerja, dengan kata lain apabila Motivasi Intrinsik meningkat maka kepuasan karyawan PT. Wibisana Marine Adventure akan semakin meningkat. Sehingga hipotesis ketiga diterima.

Perhitungan nilai koefisien determinasi total didapatkan sebesar 0,664, maka kesimpulannya adalah 66,4 persen variabel kepuasan karyawan PT. Wibisana Marine Adventure dipengaruhi oleh lingkungan kerja non fisik, dan motivasi intrinsik, sedangkan sisanya 33,6 persen dipengaruhi oleh faktor lain yang tidak dimasukkan dalam model penelitian atau diluar model penelitian

Tabel 14.

Pengaruh Langsung, Pengaruh Tidak Langsung Lingkungan Kerja Non Fisik(X), Terhadap Motivasi Intrinsik (Y1) dan Kepuasan Kerja (Y2).

\begin{tabular}{lccc}
\hline \multicolumn{1}{c}{ Pengaruh variabel } & $\begin{array}{c}\text { Pengaruh } \\
\text { langsung }\end{array}$ & $\begin{array}{c}\text { Pengaruh tidak } \\
\text { langsung melalui Y1 }\end{array}$ & Pengaruh Total \\
\hline $\mathrm{X} \rightarrow \mathrm{Y} 1$ & 0,607 & & 0,607 \\
$\mathrm{Y} 1 \rightarrow \mathrm{Y} 2$ & 0,454 & 0,276 & 0,454 \\
$\mathrm{X} \rightarrow \mathrm{Y} 2$ & 0,307 & & 0,583 \\
\hline
\end{tabular}

Sumber : Data Diolah, 2019 
Penelitian yang dilakukan di PT. Wibisana Marine Adventure mengenai pengaruh lingkungan kerja non fisik terhadap motivasi intrinsik, maka didapatkan hasil lingkungan kerja non fisik memiliki pengaruh langsung terhadap motivasi intrinsik dengan persentase sebesar 0,607 atau 60,7 persen. Penelitian yang dilakukan di PT. Wibisana Marine Adventure mengenai pengaruh motivasi intrinsik terhadap kepuasan kerja, maka didapatkan hasil motivasi intrinsik memiliki pengaruh langsung terhadap kepuasan kerja dengan persentase sebesar 0,454 atau 45,4 persen.

Penelitian yang dilakukan di PT. Wibisana Marine Adventure mengenai pengaruh lingkungan kerja non fisik terhadap kepuasan kerja, maka didapatkan hasil lingkungan kerja non fisik memiliki pengaruh langsung terhadap kepuasan kerja dengan persentase sebesar 0,307 atau 30,7 persen. Penelitian yang dilakukan di PT. Wibisana Marine Adventure mengenai pengaruh total lingkungan kerja non fisik dan motivasi intrinsik terhadap kepuasan kerja, maka didapatkan hasil bahwa lingkungan kerja non fisik memiliki pengaruh langsung dan tidak langsung melalui motivasi intrinsik terhadap kepuasan kerja dengan nilai koefisien masing-masing sebesar 0,307 dan 0,276, sehingga besaran pengaruh totalnya adalah 0,583 atau 58,3 persen.

Hasil hipotesis dalam penelitian ini menunjukkan bahwa lingkungan kerja non fisik memiliki pengaruh positif dan signifikan terhadap motivasi intrinsik, dengan kata lain semakin baik lingkungan kerja non fisik PT. Wibisana Marine Adventure, maka semakin tinggi tingkat motivasi intrinsik PT. Wibisana Marine Adventure. Sehingga hipotesis pertama diterima. Penerapan lingkungan kerja non fisik seperti adanya pelayanan terhadap karyawan dari segi keselamatan dalam bekerja akan membuat karyawan merasa aman dan nyaman sehingga dapat memotivasi diri pegawai secara intrinsik untuk menyelesaikan pekerjaan. Sikap kepemimpinan dan hubungan kerja karyawan yang merupakan bagian dari lingkungan kerja non fisik karyawan dapat membentuk motivasi intrinsik yang ada dalam diri karyawan saat melaksanakan pekerjaannya.

Setyadi et al. (2015) menemukan lingkungan kerja non fisik berpengaruh positif dan signifikan terhadap kepuasan kerja. Suwarsito (2016) menemukan lingkungan kerja non fisik secara signifikan berpengaruh terhadap motivasi kerja karyawan Wahana Visi Indonesia. Sentosa \& Riana (2018) dalam penelitiannya menyatakan lingkungan kerja non fisik memiliki pengaruh positif dan signifikan terhadap motivasi intrinsik pada pegawai di dinas pendapatan Daerah Badung Mangusada.

Hasil hipotesis dalam penelitian ini menunjukkan bahwa lingkungan kerja non fisik berpengaruh positif dan signifikan terhadap kepuasan kerja dengan kata lain semakin baik lingkungan kerja non fisik maka kepuasan karyawan PT. Wibisana Marine Adventure akan semakin meningkat. Sehingga hipotesis kedua diterima. Hal ini sejalan dengan hasil penelitian yang dilakukan oleh Jain \& Kaur (2015) dalam penelitiannya menemukan bahwa beban kerja, setres, lembur, kelelahan, kebosanan adalah beberapa faktor untuk meningkatkan ketidak puasan kerja. Pada fasilitas kondisi kerja yang baik sisi lain, penyegaran dan fasilitas rekreasi, kesehatan dan keselamatan, menyenangkan di tempat kerja meningkatkan tingkat kepuasan kerja. 
Osibanjo et al. (2015) menemukan bahwa menyediakan lingkungan kerja yang kondusif, cukup terjamin dan memastikan menyeimbangkan pekerjaan dengan keluarga dan memastikan bahwa beban pekerjaan tidak melebihi batas. Pangarso \& Ramadhyanti (2015) menyatakan bahwa lingkungan kerja non fisik berpengaruh positif dan signifikan terhadap kepuasan kerja. Eka et al. (2016) menyatakan hasil dari penelitiannya bahwa lingkungan kerja non fisik berpengaruh positif dan signifikan terhadap kepuasan kerja pada PT. Telkom Indonesia Witel Jatim. Sentosa \& Riana (2018) menyatakan lingkungan kerja non fisik memiliki pengaruh positif dan signifikan terhadap kepuasan kerja pada pegawai di dinas pendapatan Daerah Badung Mangusada.

Hasil hipotesis dalam penelitian ini menunjukkan bahwa motivasi intrinsik memiliki pengaruh positif dan signifikan terhadap kepuasan kerja, dengan kata lain apabila motivasi intrinsik meningkat maka kepuasan karyawan PT. Wibisana Marine Adventure akan semakin meningkat. Sehingga hipotesis ketiga diterima. motivasi dalam cangkupannya secara intrinsik dan ekstrinsik merupakan faktor penting dalam menentukan kepuasan dan kinerja karyawan. Ibrahim \& Brobbey (2015) menyatakan tentang motivasi, dimana motivasi ini bersifat individual karena kebutuhan individu berbeda-beda dan oleh karena itu harus ditargetkan pada kebutuhan individu dan kelompok secara intrinsik yang akan lebih memuaskan karyawan dalam bekerja.

Hasil penelitian ini sesuai dengan penelitian yang dilakukan oleh Guritno \& Prabowo (2016) menyatakan bahwa dalam penelitiannya pada karyawan PT JHOS GF Semarang bahwa semakin tinggi motivasi instrinsik yang dimiliki karyawan makan akan meningkatkan kepuasan kerja karyawan terhadap pekerjaannya. Sariningtyas (2016), menunjukkan bahwa adanya pengaruh positif antara motivasi intrinsik terhadap kepuasan kerja. Taufiq (2016) menyatakan bahwa motivasi intrinsik berpengaruh positif dan signifikan terhadap kepuasan kerja. Sentosa \& Riana (2018) dalam penelitiannya menyatakan Motivasi intrinsik memiliki pengaruh positif dan signifikan terhadap kepuasan kerja pada pegawai di dinas pendapatan Daerah Badung Mangusada. Widyaputra \& Dewi (2018) dalam penelitiannya menunjukan bahwa motivasi intrinsik memiliki pengaruh positif signifikan terhadap kepuasan kerja. Hal ini menunjukan bahwa pemberian motivasi intrinsik yang baik kepada karyawan dapat meningkatkan kepuasan kerja karyawan terhadap perusahaaannya

Implikasi teoritis dari hasil penelitin ini memberikan bukti pada pengembangan ilmu perilaku keorganisasian dan sumber daya manusia khususnya mengenai lingkungan kerja non fisik, motivasi intrinsik dan kepuasan kerja. Selain itu hasil penelitian ini secara praktis dapat menjadi salah satu acuan bagi peneliti lainnnya yang ingin meneliti mengenai lingkungan kerja non fisik, motivasi intrinsik dan kepuasan kerja. Secara teoritis penelitian ini juga memberikan pemahaman bahwa lingkungan kerja non fisik dan motivasi intrinsik secara nyata dapat meningkatkan kepuasan kerja, ketika lingkungan kerja non fisik yang diperoleh oleh karyawan meningkatkan motivasi intrinsik, maka motivasi intrinsik yang dirasakan oleh karyawan menjadi semakin kuat sehingga berpotensi meningkatkan kepuasan kerja 


\section{SIMPULAN}

Lingkungan kerja non fisik berpengaruh positif dan signifikan terhadap motivasi intrinsik. Hal ini menunjukkan bahwa jika penerapan lingkungan kerja non fisik semakin baik maka motivasi intrinsik karyawan menjadi semakin meningkat pula. Lingkungan kerja non fisik berpengaruh positif dan signifikan terhadap kepuasan kerja. Hal ini menunjukkan bahwa jika penerapan lingkungan kerja non fisik semakin baik maka kepuasan kerja karyawan menjadi semakin meningkat pula. Motivasi intrinsik berpengaruh positif dan signifikan terhadap kepuasan kerja. Hal ini menunjukkan bahwa jika penerapan motivasi intrinsik semakin baik maka kepuasan kerja karyawan menjadi semakin meningkat pula.

PT. Wibisana Marine Adventure sebaiknya dapat lebih memperhatikan pentingnya memberikan penghargaan untuk mengenali prestasi kerja karyawan. Pimpinan hendaknya mampu memberikan sebuah penghargaan atas prestasi kerja yang telah dicapai karyawannya, dalam hal ini guna meningkatkan motivasi karyawan dalam bekerja. Karena dengan meningkatnya motivasi kerja karyawan akan memberikan timbal balik terhadap kepuasan kerja karyawan. PT. Wibisana Marine Adventure sebaiknya dapat lebih memperhatikan pentingnya memberikan promosi untuk kinerja karyawan. Beberapa karyawan masih merasa pimpinan belum mampu memberikan promosi atas kinerja yang diberikan karyawan. Karena promosi yang diberikan kepada karyawan merupakan salah satu imbalan non financial. PT. Wibisana Marine Adventure sebaiknya dapat lebih memperhatikan dan memberikan dorongan serta memberikan solusi kepada karyawannya yang belum merasa puas terhadap pekerjaan yang dilakukannya. Beberapa karyawan masih belum merasa puas terhadap pekerjaan yang dilakukannya. Pemimpin dapat melakukan pendekatan terhadap karyawannya agar dapat memberikan motivasi yang tepat kepada karyawan, dengan demikian karyawan dapat merasa puas terhadap pekerjaan yang dilakukannya.

\section{REFERENSI}

Bahrulmazi, B., \& Thiam, B. (2015). The Effectiveness of Intrinsic and Extrinsic Motivations: A Study of Malaysian Amway Company's Direct Sales Forces. International Journal of Business and Social Science, 4(9), 96-103.

Celep, C., \& Yilmazturk, O. E. (2015). The Relationship Among Organizational Trust, Multidimensional Organizational Commitment and Perceived Organizational Support In Educational Organizations. Journal Social and Behavioral Sciences, 4(6), 5763-5776.

Cemal, Z., Muceldili, B., \& Sehir, S. (2015). The Moderating Effect of Ethical Climate on the Relationship between Job Satisfaction and Organizational Commitment: Evidence from Large Companies in Turkey. Journal Social and Behavioral Sciences, 5(8), 734-743. 
DeStefano, T. J., Henry, C., Megan, G., \& Thomas, P. (2006). The Relationship between Work Environment Factors and Job Satisfaction Among Rural Behavioral Health Professionals. Journal of Rural Community Psycology, 1(2), 123-127.

Eka, S., Silvia, D., Sunuharyo, B. S., \& Utami, H. N. (2016). Pengaruh Lingkungan Kerja Non Fisik Terhadap Kepuasan Kerja Dan Kinerja Karyawan PT. Telkom Indonesia Witel Jatim Selatan Malang. Jurnal Administrasi Bisnis, 40(1), 82-134.

Guritno, B., \& Prabowo, H. (2016). Analisis pengaruh motivasi intrinsic terhadap kepuasan kerja yang berdampak pada kinerja karyawan di PT. Jhons GF Semarang. Bulletin Bisnis Dan Manajemen, 2(2), 46-58.

Hande, S., Orkun, D., \& Ugur, Y. (2015). The effects of employees' perceptions of competency models on employability outcomes and organizational citizenship behavior and the moderating role of social exchange in this effect. Social and Behavioral Sciences, 15(1), 1101 - 1110.

Handy Sentosa, I. M., \& Riana, I. G. (2018). Pengaruh Lingkungan Kerja Non Fisik Terhadap Motivasi Intrinsik dan Kepuasan Kerja di Dinas Pendapatan Daerah Badung. E-Jurnal Manajemen Unud, 7(8), 4417-4446.

Hashim, Z., Waqar, S. A., \& Amir, N. M. (2015). The Impact of the Motivation on the Employee's Performance in Beverage Industry of Pakistan International. Journal of Academic Research in Accounting, Finance and Management Sciences, 4(1), 239-298.

Ibrahim, M., \& Brobbey, V. A. (2015). Impact Of Motivation On Employee Performance: The Case Of Some Selected Micro Finance Companies In Ghana. International Journal of Economics, Commerce and Management, 3(11), 1218-1236.

Izzah, N., Rini, N., \& Poernomo, B. (2019). The Influence of Non-Physical Work Environment and Job Characteristics on Employee Performance at PT. Daliatex Kusuma in Bandung. International Journal of Social Sciences Perspectives, 4(1), 22-37. https://doi.org/10.33094/7.2017.2019.41.22.37

Jain, R., \& Kaur, S. (2015). Impact Of Work Environment On Job Satisfaction. Internasional Jurnal Of Scientificand Research Publications, 4(1), 1-8.

Kabungaidze, T., \& Mahlatshana, N. (2015). The Impact of Job Satisfaction and Some Demographic Variables on Employee Turnover Intentions. International Journal of Business Administration, 4(1), 53-65.

Mahmud, M. T., Hasan, M. T., \& Asif, A. S. M. (2015). Determinants of Job 
Satisfaction: A Comparative Study in the Banking Sector of Bangladesh. International Journal of Economics and Empirical Research, 2(1), 22-28.

Naeem, A., Ihsan, F., \& Mahmood, Z. (2015). The study of Organizational justice, violation of psychological contract and its effect on job satisfaction in Paris Indrustry of Pakistan. International Journal of Academy Research in Business and Social Sciense, 4(12), 244-251.

Osibanjo, A. ., Abiodun, A., \& Adeniji, A. A. (2015). Impact of job envirotment on job satisfaction and commitment among nigeria nurses. Jurnal of South African Business and Research, 1(1), 1-11.

Pangarso, A., \& Ramadhyanti, V. (2015). Pengaruh Lingkungan Kerja Non Fisik Terhadap Kepuasan Kerja Dosen Tetap Studi Pada Fakultas Komunikasi Dan Bisnis Universitas Telkom Bandung. Journal of Business and Economics, 19(2), 1-12.

Puangyoykeaw, K., \& Nishide, Y. (2015). is there a link between compensation packages and job performance in the Ghana police service. Journal of Business Management, 7(44), 4398-4406.

Raziq, A., \& Maulabakhsh, R. (2015). Impact of Working Environment on Job Satisfaction. Procedia Economics and Finance, 23(October 2014), 717-725. https://doi.org/10.1016/s2212-5671(15)00524-9

Sariningtyas, E. R. W. (2016). Analisis Karakteristik Individu dan Motivasi Intrinsik Terhadap Komitmen Organisasi dengan Kepuasan Kerja Sebagai Variabel Intervening (Studi Pada Pdam Tirta Mulia Kabupaten Pemalang). Serat Acitya- Jurnal Ilmiah UNTAG Semarang, 5(1), 55-72.

Sentosa, I. M. H., \& Riana, I. G. (2018). Pengaruh Lingkungan Kerja Non Fisik Terhadap Motivasi Intrinsik dan Kepuasan Kerja di Dinas Pendapatan Daerah Badung. E-Jurnal Manajemen Unud, 7(8), 4417-4446.

Setyadi, B., Utami, H. N., \& Nurtjahjono, G. E. (2015). Pengaruh Lingkungan Kerja Fisik dan Non Fisik Terhadap Motivasi Kerja dan Kinerja Karyawan (Studi Pada Karyawan PT. Bank BRI, Tbk. Cabang Bogor. Jurnal Administrasi Bisnis (JAB), 21(1), 1-8.

Shurbagi, A. (2015). The Relationship between Transfornational Leadership Style Job Satisfaction and The Effect of Organizational Commitment. International Business Research, 1(1), 126-138.

Suwarsito. (2016). Analisis Pengaruh Lingkungan Kerja Non Fisik dan Motivasi Kerja terhadap Kinerja Karyawan. Open Jounal System, 1(1), 1-8. 
Taufiq, A. (2016). Pengaruh motivasi Intrinsik Terhadap Kinerja Karyawan Dengan Kepuasan Kerja Dan Disiplin Kerja Sebagai Variabel Mediasi Pada Badan Pusat Statistik Kabupaten Magelang. Journal of Business Theory and Implementation, 7(2), 88-129.

Veronica, V. F., Swasto, B., \& Djudi, M. (2018). Pengaruh Insentif Karyawan terhadap Kinerja Karyawan dengan Variabel Mediator Motivasi Kerja (Studi Pada Karyawan Bagian Pabrikan PG Kebon Agung Malang). Jurnal Administrasi Bisnis (JAB), 55(2), 139-145.

Widyaputra, K. A., \& Dewi, A. . S. K. (2018). Pengaruh Motivasi Intrinsik Terhadap Kepuasan Kerja dan Kinerja Karyawan pada PT. Bussan Auto Finance. E-Jurnal Manajemen, 7(1), 85-104. 